Pitfalls in decarbonising heat: A misalignment of Climate Policy and product energy labelling standards

\author{
PM Armstrong ${ }^{1}$, SM Bhagavathy*2, R Kang ${ }^{1}$, M McCulloch $^{2}$ \\ ${ }^{1}$ Mixergy Ltd, United Kingdom; ${ }^{2}$ University of Oxford, United Kingdom \\ *Corresponding author: sivapriya.mothilalbhagavathy@eng.ox.ac.uk
}




\section{Pitfalls in decarbonising heat: A misalignment of Climate Policy and}

\section{product energy labelling standards}

Abstract: There is considerable potential to decarbonise household energy consumption through the electrification of heating systems which can absorb excess renewable power and mitigate power network constraints through intelligent control. However, current standards discourage low carbon electricity sources through outdated assumptions; predicated upon a traditional electricity network which had higher emissions. Consequently, the implementation of product Energy labelling across Europe is biased against electric space and water heating systems in favour of gas. This paper examines the impact of this bias through a case study of the European Union's product labelling directive for domestic hot water systems. Laboratory testing of a market leading electric water tank and an A rated instantaneous gas boiler has demonstrated efficiencies of $87.4 \%$ and $72.9 \%$ respectively. In spite of this, the labelling directive assigns a $\mathrm{C}$ rating to the tank. This is due to a conversion coefficient (CC) within the directive's calculation based on an average electricity generation efficiency of $40 \%$ without a similar coefficient for gas. This paper advocates the removal of the CC factor from the directive to normalise the comparison, thus promoting a technology uniquely suited towards absorbing intermittent renewable energy sources with negligible costs.

Keywords: Energy product labelling standards; Decarbonising heat; Domestic hot water tanks; Renewable energy; Carbon intensity; Demand side management 


\section{Introduction}

Decarbonising our energy systems is a global challenge which requires a greater adoption of renewable energy sources ${ }^{1}$. The thermal inertia of buildings with electric space and water heating systems can help balance the increased variability from renewables by acting as a low-cost storage service for the electricity network ${ }^{2}$. For instance, the largest surpluses of renewable power production that arise on the UK's electricity balancing market could be absorbed if a few percent of the country's domestic electric hot water tanks were controlled more intelligently ${ }^{3}$. Furthermore, an analysis of the potential for demand response across Northern European countries indicated that peak power consumption could be shifted by more than $10 \%$ in member states such as Finland and Sweden where there is a high fraction of electric heating ${ }^{4}$. This is achievable given a recent survey of householder attitudes where over $30 \%$ of respondents indicated that they would allow their appliances to be controlled on their behalf to save costs ${ }^{5}$. However, due to outdated assumptions around the operation of our electricity infrastructure, European product labelling standards are inadvertently promoting gas heated systems over lower carbon electricity sources.

Historically, electrical power networks were built around large centralised thermal plant powered by fossil fuels such as coal and gas. Typically, these facilities achieved an efficiency of around $45 \%{ }^{6}$ with transmission and distribution networks incurring additional losses of $10 \%{ }^{7}$ resulting in an overall efficiency of $40 \%$ to the end user. Recent advances have now led to an increasing prevalence of distributed renewables; generation is coming closer to the point of consumption eliminating the losses associated with transmission and reducing carbon emissions further. However, a number of critical standards, influencing the design and specification of buildings and white goods, fail to recognise this phenomenon. For 
instance, in North America, the Energy Star initiative, a widely adopted scheme to benchmark the energy performance of white goods, provides an accreditation of gas heated water tanks but not for electric hot water tanks ${ }^{8}$. In addition to this, housing developers in the UK are encouraged to specify gas heating systems in order to obtain planning consent on the basis that this achieves lower carbon emissions than electrically powered alternatives $^{9}$, the same regulations also influence Energy Performance Certificates which provides an indication of a building's overall energy performance to prospective buyers. This paper highlights the way in which the European Energy Labelling directive's ${ }^{10}$ recent application to domestic hot water tanks, has been distorted by an outdated view of electricity production across member states. The consequence of this directive has been to promote the uptake of gas fuelled systems over electrically-heated systems whilst at the same time eliminating a valuable source of flexible electrical load which can help facilitate more renewable generation. This is in spite of the fact that now over $20 \%$ of Europe's population live in places where grid carbon intensity is lower than that of gas consumption, see Figure $5 b$.

We begin with a description of the test standard in Section 2 to provide context behind experimental analysis undertaken for this paper. Section 3 details the methods used to conduct the experiments allowing us to compare the efficiency of different domestic water heating systems. The results of these experiments demonstrate that in spite of being more efficient, the electric hot water tank is awarded a $\mathrm{C}$ rating against an $\mathrm{A}$ rating for the instantaneous gas boiler. This finding precipitates a discussion on the implications that this structural bias within the standard has towards gas consumption against the wider context of trends towards decarbonisation within our electric systems followed by conclusions in Section 5. 


\section{How energy labels are generated for domestic hot water tanks}

Standard EU $812 / 2013^{10}$ details the test used to determine the efficiency of instantaneous gas boilers and electric hot water tanks, cross-sections of which are shown in Figure 1. For electrically heated systems, a Conversion Coefficient (CC) is introduced to account for the generation efficiency of electric power production. The figure assumes an averaged conversion efficiency of $40 \%$ across the EU's entire electricity generation fleet irrespective of the geographic location of the hot water systems. Systems powered by gas, however, do not have any associated CC value, implicitly assuming that there are no losses associated with the generation and distribution of gas. The consequence of this is that it is numerically impossible for electric hot water cylinders to obtain a rating higher than a B whereas instantaneous gas boiler systems can comfortably obtain an A.
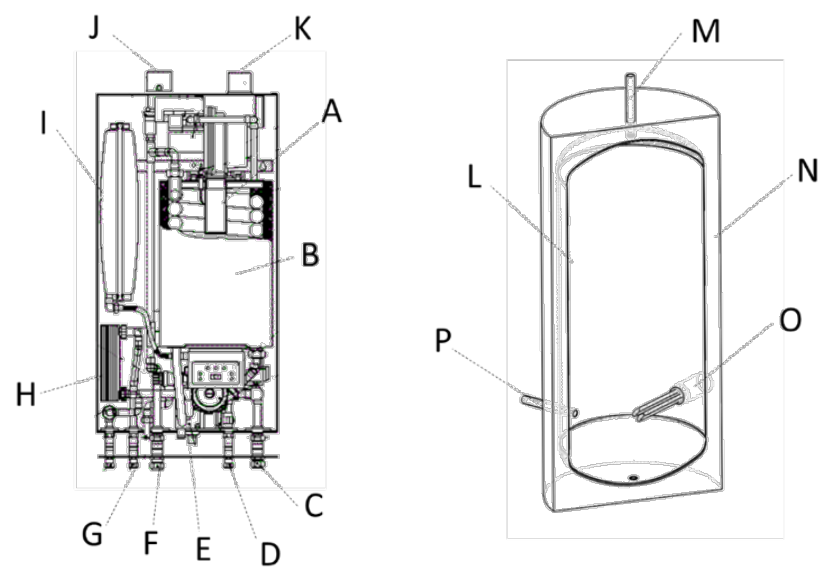

Figure 1: Cross section detail through an instantaneous gas boiler ${ }^{11}$ (left) and a hot water tank (right) where $\mathbf{A}$ is the gas burner within the boiler, $\mathbf{B}$ is the primary heat exchanger warming a warmer glycol circuit which heats the domestic hot water heat exchanger H. C and $\mathbf{D}$ are connections for space heating. $\mathbf{E}$ is a drain point for condensation which collects during heat recovery within the flue. $\mathbf{F}$ and $\mathbf{G}$ are the domestic hot water flow and return connections whilst $\mathbf{I}$ is an internal expansion vessel to cater to water's changing volume as it heats. $\mathbf{J}$ and $\mathbf{K}$ are the flue air inlet and exhaust outlet connections respectively. On the hot water tank, $\mathbf{P}$ shows the inlet connection through which cold water enters the tank $\mathbf{L}$. Hot water is pushed out of the top of the cylinder through the outlet $\mathbf{M}$. The cylinder is covered by a jacket of insulation, $\mathbf{N}$, and heated by an electric immersion element $\mathbf{O}$ 
Figure 2a illustrates the testing arrangement that enables a manufacturer of domestic hot water systems to score their product according to standard EU 812/2013. The hot water tank or boiler must operate within an ambient temperature of $20^{\circ} \mathrm{C}+/-1^{\circ} \mathrm{C}$ throughout the test. A metered fuel source provides heat to the system which draws cold inlet water at $10^{\circ} \mathrm{C}+/-1^{\circ} \mathrm{C}$ whenever a draw event is initiated by the flow control system.

The draw events are defined by a table of draw profiles reflecting the size of the system. Systems are sized from extra-small through to extra-large each having a corresponding draw profile prescribing the amount of energy, flow rate and time of day associated with each individual draw event. Figure $2 \mathrm{~b}$ shows the flow rates and amounts of energy extracted during draw events from small to large households.

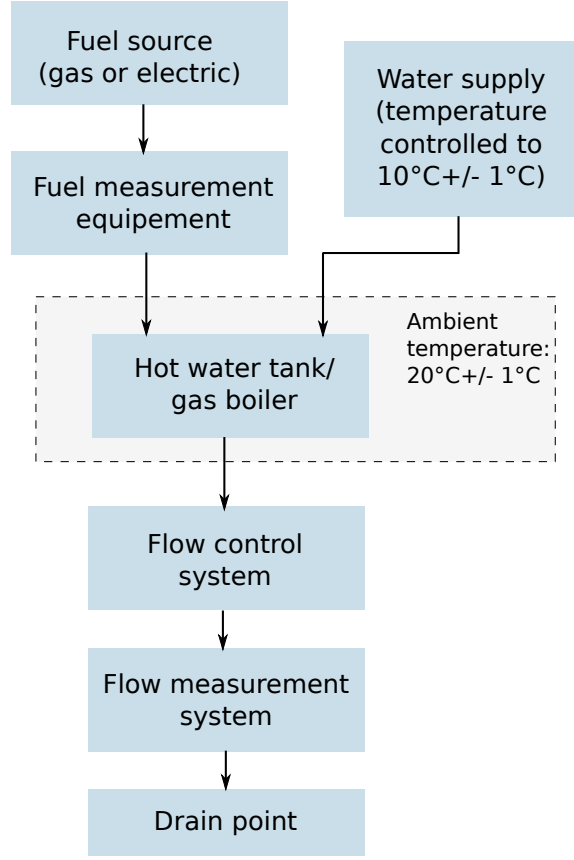

b
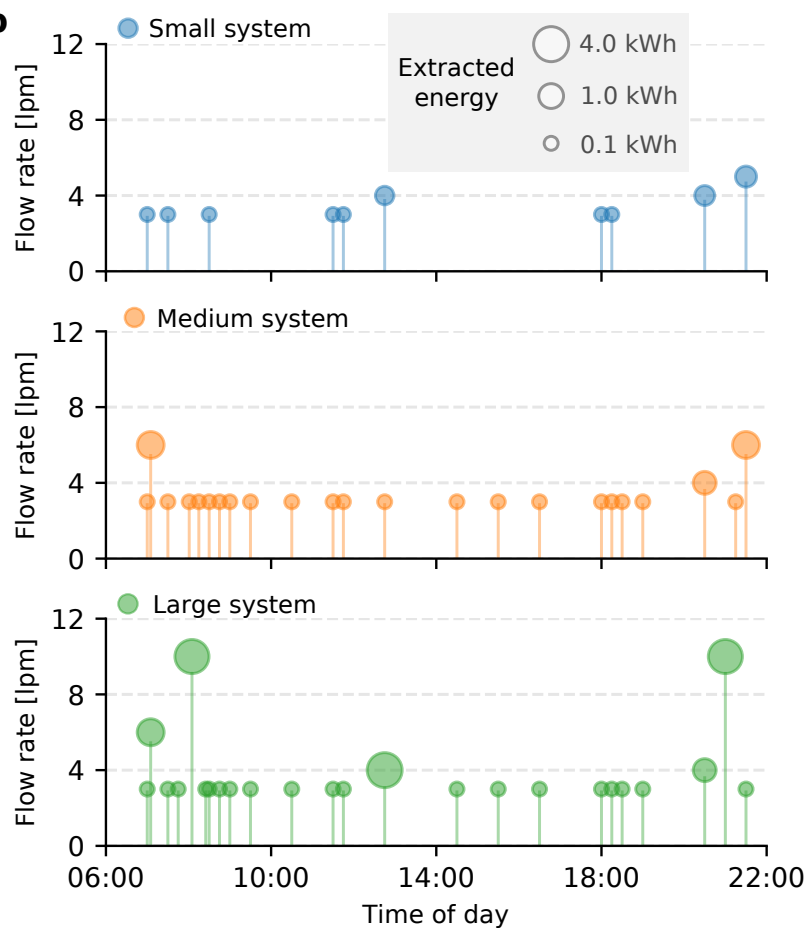

Figure 2: a: A flow diagram describing the test equipment associated with EU 812/2013. b: Stem plots showing the flow rates (y-axis) and draw energies (marker size) associated with a Small $\left(Q_{r e f}=2.1 \mathrm{kWh}\right)$, Medium $\left(Q_{\text {ref }}=5.845 \mathrm{kWh}\right)$ and Large $\left(Q_{r e f}=11.655 \mathrm{kWh}\right)$ sized system. The area of the markers is proportional to the extracted energies. 
The medium and large draw profiles extract $5.845 \mathrm{kWh}$ and $11.655 \mathrm{kWh}$ respectively. The majority of tank sizes encountered in domestic markets are between 100 litres and 200 litres which corresponds to medium and large draw profiles respectively*. Both of these profiles contain several, relatively large, draw events scattered throughout the day at flow rates as high as $10 \mathrm{lpm}$ along with numerous small draw events at a lower flow rate of $3 \mathrm{lpm}$. This draw pattern is designed to reflect the typical usage pattern associated with a European household.

The test commences with an initial warm-up and 12-hour stabilisation period before a 24hour draw cycle is executed. For systems that are designed to adapt to changing user behaviour, a 'smart factor' is introduced and the test lasts for two weeks with a randomisation between two adjacent draw cycle sizes. For the purposes of this paper, the smart factor won't be considered as it has a relatively negligible contribution to the final efficiency score. The fuel measurement equipment, indicated in Figure $2 \mathrm{a}$, records the total energy consumed which is either electric, $Q_{\text {elec }}$, or some other form of fuel including gas, $Q_{f u e l}$. Some systems may include a mixture of different fuels and so both variables may come into play. The final efficiency is determined by Equation 1:

$$
\eta_{w h}=\frac{Q_{\text {ref }}}{\left(Q_{\text {fuel }}+C C \cdot Q_{\text {elec }}\right)(1-S C F \cdot \text { smart })+Q_{\text {cor }}}
$$

where, $Q_{r e f}$ is the energy drawn from the system according to the draw profile and $S C F$. smart is the smart factor which is not considered in this paper as discussed. $Q_{c o r}$ is a correction factor:

$$
Q_{\text {corr }}=-k \cdot\left(C C \cdot\left(Q_{\text {elec }} \cdot(1-S C F \cdot \operatorname{smart})-Q_{\text {ref }}\right)\right.
$$

\footnotetext{
${ }^{*}$ We assume here that heat is dispatched at $60^{\circ} \mathrm{C}$ and that the inlet temperature is at $10^{\circ} \mathrm{C}$.
} 
where $k$, the correction coefficient, is determined by the system size as given in table 8 of the directive EU812/2013 ${ }^{10}$.

For systems involving a thermostatically controlled hot water tank, the electricity consumption, $Q_{\text {elec }}$, must be corrected to account for the changing temperature associated with the thermostat's hysteresis margin after the tank's first warm-up prior to the draw cycle compared to the reheat at the end of the draw cycle. This correction is detailed in standard BS EN 50440:2015 by equation 5 along with the measurement process used to obtain the hysteresis temperature ${ }^{12}$.

The parameter which has the greatest bearing on the performance of electrically heated water tanks is $C C$, the conversion coefficient. $C C$ only applies to the electricity consumption, $Q_{\text {elec }}$ and assumes a value of 2.5. This implies that the efficiency of electrical generation, transmission and distribution is $40 \%$. It is this assumption which underpins the bias that the standard has towards gas heating.

Table 1: Mapping of energy labelling scheme efficiency calculation and the labelling score ${ }^{10}$ (The efficiency calculated using equation 1 is mapped to this table to arrive at the energy label score for the product under consideration.)

\begin{tabular}{|c|c|c|c|c|c|c|c|c|}
\hline & $3 X S$ & XXS & XS & $S$ & $M$ & $\mathrm{~L}$ & $X \mathrm{~L}$ & $X X L$ \\
\hline $\mathrm{A}^{+++}$ & $\eta_{w h} \geq 62$ & $\eta_{w h} \geq 62$ & $\eta_{w h} \geq 69$ & $\eta_{w h} \geq 90$ & $\eta_{w h} \geq 163$ & $\eta_{w h} \geq 188$ & $\eta_{w h} \geq 200$ & $\eta_{w h} \geq 213$ \\
\hline $\mathrm{A}^{++}$ & $\begin{array}{l}53 \leq \eta_{w h}< \\
62\end{array}$ & $\begin{array}{l}53 \leq \eta_{w h}< \\
62\end{array}$ & $\begin{array}{l}61 \leq \eta_{w h}< \\
69\end{array}$ & $\begin{array}{l}72 \leq \eta_{w h}< \\
90\end{array}$ & $\begin{array}{l}130 \leq \eta_{w h}< \\
163\end{array}$ & $\begin{array}{l}150 \leq \eta_{\mathrm{wh}}< \\
188\end{array}$ & $\begin{array}{l}160 \leq \eta_{w h}< \\
200\end{array}$ & $\begin{array}{l}170 \leq \eta_{w h}< \\
213\end{array}$ \\
\hline$A^{+}$ & $\begin{array}{l}44 \leq \eta_{w h}< \\
53\end{array}$ & $\begin{array}{l}44 \leq \eta_{\text {wh }}< \\
53\end{array}$ & $\begin{array}{l}53 \leq \eta_{w h}< \\
61\end{array}$ & $\begin{array}{l}55 \leq \eta_{w h}< \\
72\end{array}$ & $\begin{array}{l}100 \leq \eta_{\text {wh }}< \\
130\end{array}$ & $\begin{array}{l}115 \leq \eta_{w h}< \\
150\end{array}$ & $\begin{array}{l}123 \leq \eta_{w h}< \\
160\end{array}$ & $\begin{array}{l}131 \leq \eta_{w h}< \\
170\end{array}$ \\
\hline A & $\begin{array}{l}35 \leq \eta_{w h}< \\
44\end{array}$ & $\begin{array}{l}35 \leq \eta_{w h}< \\
44\end{array}$ & $\begin{array}{l}38 \leq \eta_{w h}< \\
53\end{array}$ & $\begin{array}{l}38 \leq \eta_{w h}< \\
55\end{array}$ & $\begin{array}{l}65 \leq \eta_{\text {wh }}< \\
100\end{array}$ & $\begin{array}{l}75 \leq \eta_{w h}< \\
115\end{array}$ & $\begin{array}{l}80 \leq \eta_{w h}< \\
123\end{array}$ & $\begin{array}{l}85 \leq \eta_{w h}< \\
131\end{array}$ \\
\hline B & $\begin{array}{l}32 \leq \eta_{w h}< \\
35\end{array}$ & $\begin{array}{l}32 \leq \eta_{w h}< \\
35\end{array}$ & $\begin{array}{l}35 \leq \eta_{w h}< \\
38\end{array}$ & $\begin{array}{l}35 \leq \eta_{w h}< \\
38\end{array}$ & $\begin{array}{l}39 \leq \eta_{\text {wh }}< \\
65\end{array}$ & $\begin{array}{l}50 \leq \eta_{w h}< \\
75\end{array}$ & $\begin{array}{l}55 \leq \eta_{w h}< \\
80\end{array}$ & $\begin{array}{l}60 \leq \eta_{w h}< \\
85\end{array}$ \\
\hline C & $\begin{array}{l}29 \leq \eta_{w h}< \\
32\end{array}$ & $\begin{array}{l}29 \leq \eta_{w h}< \\
32\end{array}$ & $\begin{array}{l}32 \leq \eta_{w h}< \\
35\end{array}$ & $\begin{array}{l}32 \leq \eta_{w h}< \\
35\end{array}$ & $\begin{array}{l}36 \leq \eta_{w h}< \\
39\end{array}$ & $\begin{array}{l}37 \leq \eta_{w h}< \\
50\end{array}$ & $\begin{array}{l}38 \leq \eta_{w h}< \\
55\end{array}$ & $\begin{array}{l}40 \leq \eta_{\text {wh }}< \\
60\end{array}$ \\
\hline D & $\begin{array}{l}26 \leq \eta_{w h}< \\
29\end{array}$ & $\begin{array}{l}26 \leq \eta_{\text {wh }}< \\
29\end{array}$ & $\begin{array}{l}29 \leq \eta_{w h}< \\
32\end{array}$ & $\begin{array}{l}29 \leq \eta_{w h}< \\
32\end{array}$ & $\begin{array}{l}33 \leq \eta_{\text {wh }}< \\
36\end{array}$ & $\begin{array}{l}34 \leq \eta_{w h}< \\
37\end{array}$ & $\begin{array}{l}35 \leq \eta_{w h}< \\
38\end{array}$ & $\begin{array}{l}36 \leq \eta_{\text {wh }}< \\
40\end{array}$ \\
\hline$E$ & $\begin{array}{l}22 \leq \eta_{w h}< \\
26\end{array}$ & $\begin{array}{l}23 \leq \eta_{\text {wh }}< \\
26\end{array}$ & $\begin{array}{l}26 \leq \eta_{w h}< \\
29\end{array}$ & $\begin{array}{l}26 \leq \eta_{w h}< \\
29\end{array}$ & $\begin{array}{l}30 \leq \eta_{w h}< \\
33\end{array}$ & $\begin{array}{l}30 \leq \eta_{w h}< \\
34\end{array}$ & $\begin{array}{l}30 \leq \eta_{w h}< \\
35\end{array}$ & $\begin{array}{l}32 \leq \eta_{\text {wh }}< \\
36\end{array}$ \\
\hline $\mathrm{F}$ & $\begin{array}{l}19 \leq \eta_{w h}< \\
22\end{array}$ & $\begin{array}{l}20 \leq \eta_{w h}< \\
23\end{array}$ & $\begin{array}{l}23 \leq \eta_{w h}< \\
26\end{array}$ & $\begin{array}{l}23 \leq \eta_{w h}< \\
26\end{array}$ & $\begin{array}{l}27 \leq \eta_{w h}< \\
30\end{array}$ & $\begin{array}{l}27 \leq \eta_{w h}< \\
30\end{array}$ & $\begin{array}{l}27 \leq \eta_{w h}< \\
30\end{array}$ & $\begin{array}{l}28 \leq \eta_{\text {wh }}< \\
36\end{array}$ \\
\hline G & $\eta_{w h}<19$ & $\eta_{w h}<20$ & $\eta_{w h}<23$ & $\eta_{w h}<23$ & $\eta_{w h}<27$ & $\eta_{w h}<27$ & $\eta_{w h}<27$ & $\eta_{w h}<28$ \\
\hline
\end{tabular}


The mapping of the final labelling against the efficiency calculated by Equation 1 is determined by Table 1.

\section{Method}

This section explains the test set-up, computation and analysis required to conduct the experiments described in the European labelling standard governing domestic hot water systems.

\subsection{Experimental apparatus}

In order to compare the performance of an electric hot water tank and instantaneous gas boiler, a test facility, implementing the arrangement illustrated in Figure 2a, was designed and built. Figure 3 shows the key attributes of the system. During the test, the draw events, depicted in Figure $2 \mathrm{~b}$, are controlled by the flow control manifold (I) which is detailed further in Figure 3. Measurement of inlet and outlet temperatures to the tank, $t 1$ and $t 3$, along with the boiler, $\mathrm{t} 4$ and $\mathrm{t} 5$, is achieved using PT100 temperature sensors which have an error below $+/-0.3^{\circ} \mathrm{C}$. The sensors have a diameter of $0.5 \mathrm{~mm}$ to ensure a response time of less than 0.5 seconds.

\subsection{Computing the energy efficiency}

The total energy measured from the boiler or electric hot water tank, $Q_{t o t}$, is determined by a summation of the energy associated with each measured draw event $Q_{d i}$, from event $i=1$ to $i=j$ where $j$ denotes the last draw event of the test cycle:

$$
Q_{t o t}=\sum_{i=1}^{j} Q_{d i}
$$

The test rig operates the timing of the solenoid valves by computing the energy extracted from the instantaneous gas boiler or the electric hot water tank in real time. This 
computation is made on the basis of the measured flow rate, $m \dot{(t)}$, outlet

temperature, $T_{o}(t)$, and cold inlet temperature $T_{c}(t)$ which all vary according to time, $t$,

during the test. Each draw event is considered complete when the measured energy

consumption, $Q_{d i}$, equals the target draw energy, $Q_{t j}$, as detailed by the standard and

shown in Figure 2 b. $Q_{d j}$ is calculated by the rig control computer according to the following

formula:

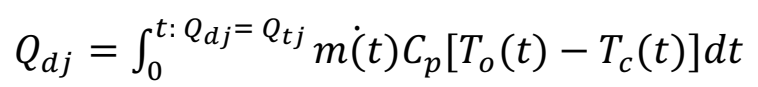

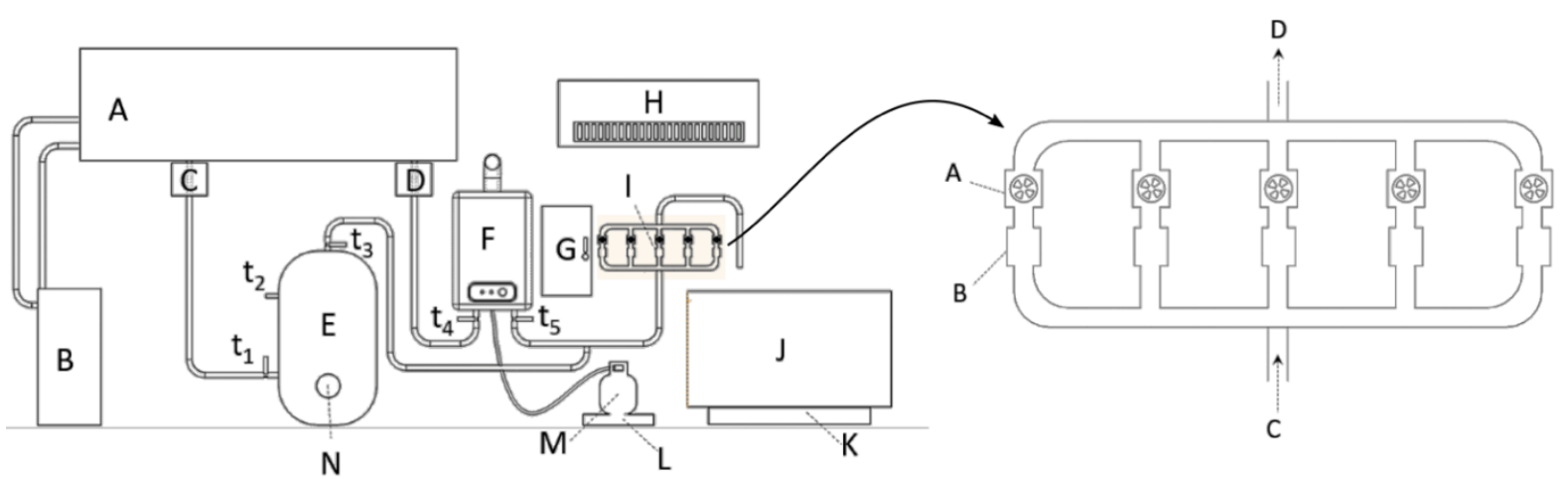

Figure 3: Schematic showing key systems within the test facility used to compare electric hot water tank and instantaneous gas boiler efficiencies. Right: Inset showing flow control manifold to sequence draw events from the electric hot water tank/gas boiler. A 500 litre header tank $\mathbf{A}$ stores chilled water produced by refrigeration plant $\mathbf{B}$ at a temperature of $10^{\circ} \mathrm{C}$ to within $+/-0.5^{\circ} \mathrm{C}$. The chilled water makes its way to either the tank or the boiler inlet connections via inlet management systems $\mathbf{C}$ and $\mathbf{D}$. The inlet management systems include a pump, expansion vessel and pressure reducing valve to maintain a delivery pressure of 3 bar +/- 0.1 bar. In addition, the inlet management systems include a purge system to circulate the chilled water from the header tank up to the appliance delivery connections to ensure that consistent cold water temperatures are attained within $100 \mathrm{~mm}$ of the tank or boiler without being influenced by ambient conditions. The inlet water flows through either the tank $\mathbf{E}$ or the gas boiler $\mathbf{F}$ depending on which system is being tested. The operation of the test rig is co-ordinated by a control cabinet $\mathbf{G}$ which contains a PLC driven by a host computer outside of the test room. The test room's temperature is maintained to $20^{\circ} \mathrm{C}+/-1^{\circ} \mathrm{C}$ by a thermostatically controlled air conditioning unit $\mathbf{H}$. The draw events are controlled by the flow control manifold $\mathbf{I}$. The water discharges through the flow control manifold into a measuring sump $\mathbf{J}$ which has its weight tracked by precision sump scales $\mathbf{K}$ to infer the mass flow rate. A set of precision scales (L) also measures the changing weight of the gas canister $\mathbf{M}$ supplying the gas boiler $\mathbf{F}$. The control cabinet $\mathbf{G}$ contains an energy logger to record the electricity consumption within the immersion heater $\mathbf{N}$ which powers the tank under test $\mathbf{E}$. A set of manual throttling valves $A$ along five flow branches allows the flow rate associated with each draw event, shown in Figure $2 \mathrm{~b}$, to be calibrated. Normally closed solenoid gate valves $\mathbf{B}$ select the flow branch associated with each draw event and its corresponding flow rate. Water comes in through the manifold inlet $\mathbf{C}$ before taking the selected flow branch and exiting through the manifold outlet $\mathbf{D}$. 
The energy input to the gas boiler or electric hot water tank, $Q_{i n}$, is determined either by measurement of the mass of gas consumed during the test, $m_{\text {gas }}$, multiplied by the gravimetric calorific content $G_{g v}$ or the electric energy consumed by the hot water tank's

heating element, $Q_{\text {elec }}$ using an electricity meter:

$Q_{\text {in }}=\left\{\begin{array}{l}m_{\text {gas }} G_{g v}, \text { if } g a s \\ Q_{\text {elec }}, \text { if electric }\end{array}\right.$

The resulting efficiency of either the gas boiler or the electric hot water tank is determined by:

$$
\eta_{\text {actual }}=\frac{Q_{\text {tot }}}{Q_{\text {in }}}
$$

\subsection{Determining the errors associated with the test}

To determine the errors associated with the test, we consider the influence of each source of instrumentation error on the real-time measurement of $Q_{d j}$ along with the input measurement $Q_{i n}$. Beginning with, $Q_{d j}$, a conservative approach is taken in this paper. Errors can be taken in quadrature where measurements are independent of one another ${ }^{13}$. However, as central apparatus was involved in the temperature measurements (e.g. a single instrumentation amplifier and cold junction for thermocouples), there are potential common sources of error and so a worst-case estimate was made on the basis of the following treatment of equation 4 which assumes that errors could be adversely correlated:

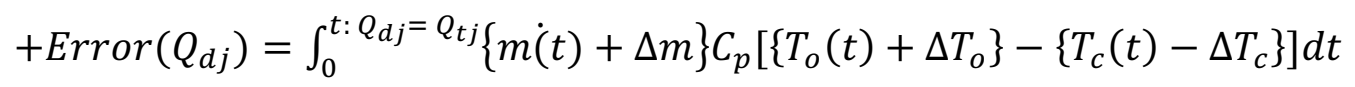

and:

$$
-\operatorname{Error}\left(Q_{d j}\right)=\int_{0}^{t: Q_{d j}=Q_{t j}}\{m \dot{(t)}-\Delta m\} C_{p}\left[\left\{T_{o}(t)-\Delta T_{o}\right\}-\left\{T_{c}(t)+\Delta T_{c}\right\}\right] d t
$$


The input error associated with $Q_{\text {in }}$ can be simply determined from the stated accuracy of the gas bottle scales or the electricity meter for the gas boiler or electric hot water tank respectively. Table 2 lists the key sources of error considered in this analysis. In addition, to determine the error associated with instrumentation, measurements of efficiency for both the instantaneous gas boiler and the electric hot water tank were repeated three times to determine the test repeatability.

Table 2: Errors associated with key instrumentation.

\begin{tabular}{l|c|c} 
Parameter & Equipment & Error \\
\hline Inlet temperature & Platinum resistance thermometer & $+/-0.3^{\circ} \mathrm{C}$ \\
Outlet temperature & Platinum resistance thermometer & $+/-0.3^{\circ} \mathrm{C}$ \\
Internal water temperature & T-type thermocouple & $+/-0.5^{\circ} \mathrm{C}$ \\
Ambient temperature & T-type thermocouple & $+/-0.5^{\circ} \mathrm{C}$ \\
Water mass measurement & UKAS calibrated scales & $+/-0.05 \mathrm{~kg}$ \\
Gas mass measurement & UKAS calibrated scales & $+/-0.001 \mathrm{~kg}$
\end{tabular}

\section{Experimental Results}

A market leading instantaneous gas combination boiler and mains pressurised hot water cylinder were measured against the medium draw profile shown in the middle subplot of Figure 2b. The boiler selected was a Keston C30 Propane variant with a rated output of 30 kW. The hot water cylinder was a Heatrae Sadia Megaflo ECO 125DD which is a direct electric system with a 125 litre storage capacity, see Figure 4a.

The top subplot in Figure $4 \mathrm{~b}$ shows the temperature trace at the outlet of the hot water tank during one test where a consistent outlet temperature of $60^{\circ} \mathrm{C}+/-1^{\circ} \mathrm{C}$ was maintained throughout. As the outlet sensor location was downstream of the insulated water tank, the temperature dropped between draw events to a steady state lower than $60^{\circ} \mathrm{C}$ due to the thermal path to ambient explaining the 'sawtooth' profile observed during the draw cycle. The bottom subplot in Figure $4 \mathrm{~b}$ shows the electricity consumption associated with the hot 
water tank during the same test. The average efficiencies across the testing stood at $72.9 \%+/-2.9 \%$ for the instantaneous gas boiler and $87.4 \%+/-2.3 \%$ for the electric hot water tank. The error associated with the instantaneous gas boiler was slightly higher due to the increased uncertainty associated with the gas bottle scale measurement in comparison to the electric tank's electricity meter. In terms of repeatability, the three tests for both the instantaneous gas boiler and electric hot water tank exhibited a standard deviation of $1.2 \%$. In other words, the errors associated with the instrumentation were more significant than the uncertainty around test repeatability (see Figure 4c).

The performance of an instantaneous gas boiler is sensitive to weather conditions as the air inlet temperature and humidity will influence the heat losses from the internal burners. The gas boiler testing was conducted in late June over the course of three days during which the average outdoor air temperature ranged between $10^{\circ} \mathrm{C}$ and $16^{\circ} \mathrm{C}$ with a range of humidity of $55 \%$ to $80 \%$. There was a slight increase in instantaneous gas boiler efficiency on the warmest, most humid day of testing from $71.6 \%$ to $74.3 \%$ for outdoor temperatures and relative humidity values of $10^{\circ} \mathrm{C}$ to $16^{\circ} \mathrm{C}$ and $67 \%$ to $80 \%$ respectively (see Table 3). For reference, the annual average UK outdoor temperature was $10.6^{\circ} \mathrm{C}$ throughout $2017^{14}$. All tests were performed with the inlet water temperature controlled at $10^{\circ} \mathrm{C}+/-0.5^{\circ} \mathrm{C}$ via a 500 litre header tank and circulating chiller system as shown in Figure 3. 
a

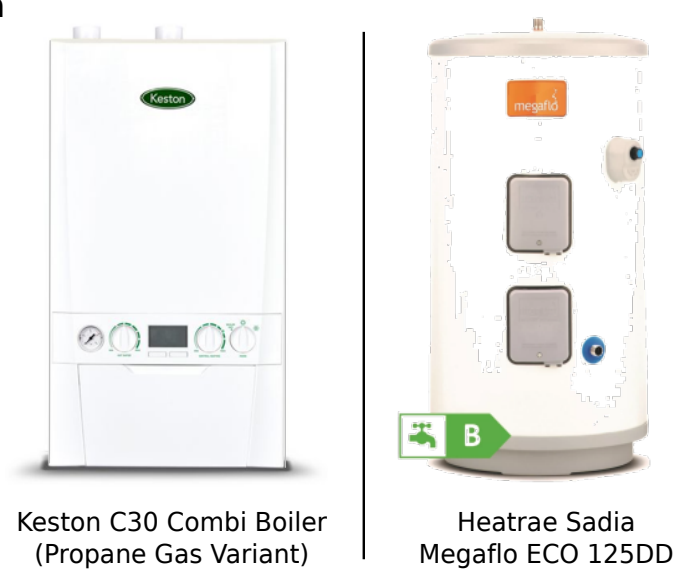

b

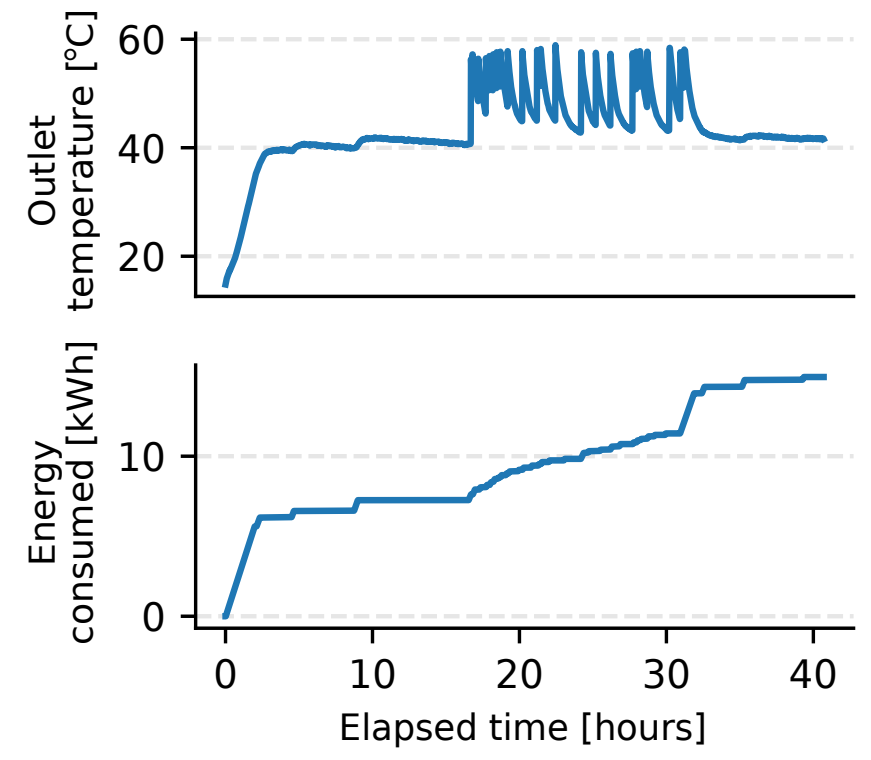

C Gas boiler Electric tank

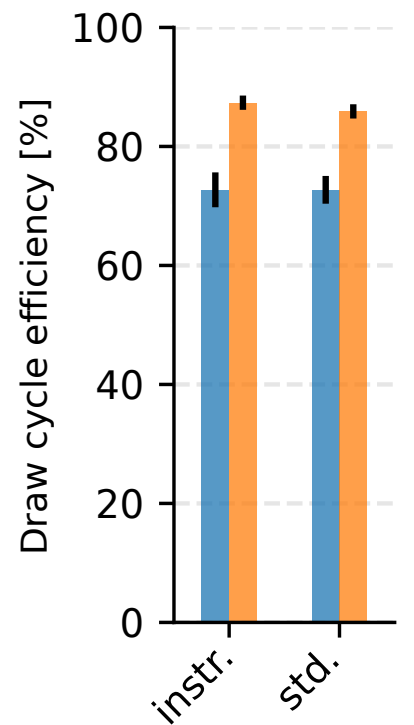

Figure 4 a: Product images of the two systems compared on the test rig. $\mathbf{b}$ : Example outlet temperature (top) and energy consumption (bottom) profiles during hot water tank test. c: Bar graphs showing the average efficiency measured across three experiments for both the instantaneous gas boiler and the electric tank. These bar graphs are annotated with vertical error bars (in black) to show separately the instrumentation error (instr) and one standard deviation (std) across the experiments. 
Table 3: Final test results.

\begin{tabular}{|c|c|c|c|c|c|c|c|c|}
\hline Test & Test date & $\begin{array}{c}\text { System } \\
\text { under } \\
\text { test }\end{array}$ & $\begin{array}{c}Q_{t o t} \\
\text { (kWh) }\end{array}$ & $\begin{array}{c}Q_{i n}(\mathrm{kWh}) \\
\text { [mass of gas } \\
\text { consumption] } \\
\text { (g) }\end{array}$ & $\begin{array}{c}\text { Efficiency (\%) } \\
\text { [instrumentation } \\
\text { error] }\end{array}$ & $\begin{array}{c}\text { Ambient } \\
\text { Temp } \\
\left({ }^{\circ} \mathrm{C}\right)\end{array}$ & $\begin{array}{c}\text { Average } \\
\text { Outdoor } \\
\text { Temp } \\
\left({ }^{\circ} \mathrm{C}\right)\end{array}$ & $\begin{array}{c}\text { Average } \\
\text { Outdoor } \\
\text { Humidity } \\
(\%)\end{array}$ \\
\hline 1 & 20/06/2018 & Gas & 6.24 & $8.40[605]$ & $74.3[+/-2.9]$ & $20+/-3$ & 16 & 80 \\
\hline 2 & $21 / 06 / 2018$ & Gas & 6.24 & 8.65 [623] & $72.1[+/-2.9]$ & $20+/-3$ & 11 & 55 \\
\hline 3 & $22 / 06 / 2018$ & Gas & 6.25 & 8.72 [628] & $71.6[+/-2.9]$ & $20+/-3$ & 10 & 67 \\
\hline 4 & $23 / 07 / 2018$ & Electric & 6.34 & 7.34 & $88.9[+/-2.3]$ & $20+/-3$ & NA & NA \\
\hline 5 & $25 / 07 / 2018$ & Electric & 6.35 & 7.52 & $86.0[+/-2.3]$ & $20+/-3$ & NA & NA \\
\hline 6 & $04 / 10 / 2017$ & Electric & 6.51 & 7.43 & $88.0[+/-2.3]$ & $20+/-3$ & NA & NA \\
\hline
\end{tabular}

In spite of the measurement errors, the experiments clearly demonstrated that the electric hot water tank outperformed the instantaneous gas boiler by at least $9.3 \%$ and as much as $14.5 \%$ if we consider positive and negative instrumentation errors on the average efficiency of the instantaneous gas boiler. However, whilst the instantaneous gas boiler result under the energy labelling scheme calculation (Equation 1) would remain at $72.9 \%$ when the figure for the electric hot water tank is corrected by $C C$ in the denominator of the equation, its efficiency result goes from $87.4 \%$ to $36.5 \%$. The consequence of this correction is that whilst the instantaneous gas boiler would have achieved a band $A$ according to Table 1 , the electric hot water tank scores a band $\mathrm{C}$ completely inverting the relative impression of performance against the actual efficiency measured.

There are a number of factors which may explain why the electric hot water tank delivered the draw cycle at a higher absolute efficiency in spite of the lower banding score awarded. These include: 
a. The increasing improvement in insulation standards within hot water tanks

Hot water tanks come under the remit of design standards within the UK which call for everincreasing improvements in insulation quality. Hot water tanks before the 1970 s were often uninsulated before heat loss standards led to a thickening jacket of polyurethane insulation from $25 \mathrm{~mm}$ or less in the late 70 s to over $50 \mathrm{~mm}$ today. In 2011, amendments to UK building standards mandated that heat losses had to be dropped by $11 \%$ with respect to allowable performance in $2008^{15}$. This ratcheting up of insulation performance has led to a significant drop in heat losses, the primary penalty associated with hot water storage.

b. The overhead of indirect heat exchange within a gas boiler

Within an instantaneous gas boiler, the burners are isolated from the domestic hot water via a plate heat exchanger and secondary heat transfer fluid, see Figure 1 . The secondary heat transfer fluid provides heat transfer for space heating and contains anti-corrosion and anti-scale additives to prevent the system from fouling up. There is, however, an efficiency penalty associated with the temperature drop across this heat transfer equipment. Electric hot water tanks can heat the water directly with a minimal temperature drop across the immersion's heat transfer surface.

c. Transient thermal mass losses within the gas boiler

An instantaneous gas boiler has to be sufficiently sized to cater to the highest hot water flow rates that may be encountered during operation. Consequently, the heat exchangers are oversized for most draw events. The energy invested in the thermal mass of the heat exchange equipment is lost as the boiler cools between each hot water draw event. Whilst a 
hot water tank suffers from standing heat losses, there is no cyclic thermal losses of this nature during draw events.

\section{Discussion around the energy labelling bias towards gas}

Whilst only one off-the-shelf electric hot water tank and instantaneous gas boiler were selected for the test, both systems were manufactured by the salient brands at the premium end of the UK market. The tests were also repeated three times with a detailed treatment of the sources of error associated with the experiments in-line with the typical requirements of the standards. The energy labelling scheme's bias against electric tanks could have a significant effect by driving buying trends towards instantaneous gas boilers ${ }^{16}$. At the time of formulating the energy labelling directive, the European Commission conducted a special review of the hot water system market across Europe and projected that by 2020 , instantaneous gas boilers sales would amount to 5 million units per annum compared with 4.6 million electrically heated tanks and 2.9 million indirectly heated tanks warmed from external sources such as gas system boilers, solar panels and heat pumps ${ }^{17}$ (Figure 5a). The same report asserts that across Europe, the total energy consumption associated with hot water production is equivalent to $53 \mathrm{GW}$ of power generated throughout the year which is comparable to 25 large thermal power stations. If the energy labelling directive's bias results in a significant switch from electric hot water tanks to instantaneous gas boilers, Europe could be locking itself into an increase in domestic gas consumption for decades. This raises several questions which we discuss in turn:

i. Is this policy measure justifiable on the grounds of carbon emissions?

One argument which could be advanced in favour of gas is that the carbon intensity associated with electric heating is often higher than burning fossil fuels directly where heat 
is required. The carbon intensity associated with the gross calorific value of heat from natural gas is $184 \mathrm{~g} / \mathrm{kWh}^{18}$. In 1990, the average carbon intensity of electricity production across Europe was $431 \mathrm{~g} / \mathrm{kWh}$ however this figure dropped 31\% to $295.8 \mathrm{~g} / \mathrm{kWh}$ in 2016 according to the European Environment Agency ${ }^{19}$. In addition, there is a significant variation in electric carbon intensities across the continent ${ }^{20,21,22,23}$. Figures $5 b$ and $5 c$ show carbon intensities of electricity generation in individual territories across North America and Europe respectively; a lower threshold scale, where the carbon intensity is beneath $220 \mathrm{~g} / \mathrm{kWh}$, has been selected since this indicates the point beneath which electric hot water production becomes less carbon intensive than gas according to the experiments conducted in this paper. There are a number of countries where electricity production has a lower carbon intensity than gas: Austria, Croatia, Finland, France, Latvia, Lithuania, Slovakia, Slovenia and Sweden, amounting to $23 \%$ of Europe's population.

In addition to the variation between countries, the carbon intensity of electricity generation can exhibit intense volatility in real-time. For instance, in the UK, the electric carbon intensity, when measured on a half hourly basis, was lower than gas for $14 \%$ of the time between October 2017 and October 2018 and fluctuates regularly between $100 \mathrm{~g} / \mathrm{kWh}$ and $400 \mathrm{~g} / \mathrm{kWh}^{24}$. As UK electricity production decarbonises, projections indicate that the UK grid carbon intensity will be lower than gas by 2026. If we account for the difference in efficiency between the electric hot water tank and instantaneous gas boiler tested in this paper, then the corrected carbon intensity per kWh of delivered energy of hot water indicates that electric hot water tanks will become the lower carbon option by 2020 , see Figure $5 d$. 
With the advent of internet of things and with appropriate time of use tariff, it is becoming increasingly realistic that hot water production could be delivered at a lower carbon intensity than gas. This argument becomes more compelling for tanks that are heated using heat pumps which can more than halve the electricity consumption as against direct heated systems at outdoor ambient temperatures below $0^{\circ} \mathrm{C}^{25}$.

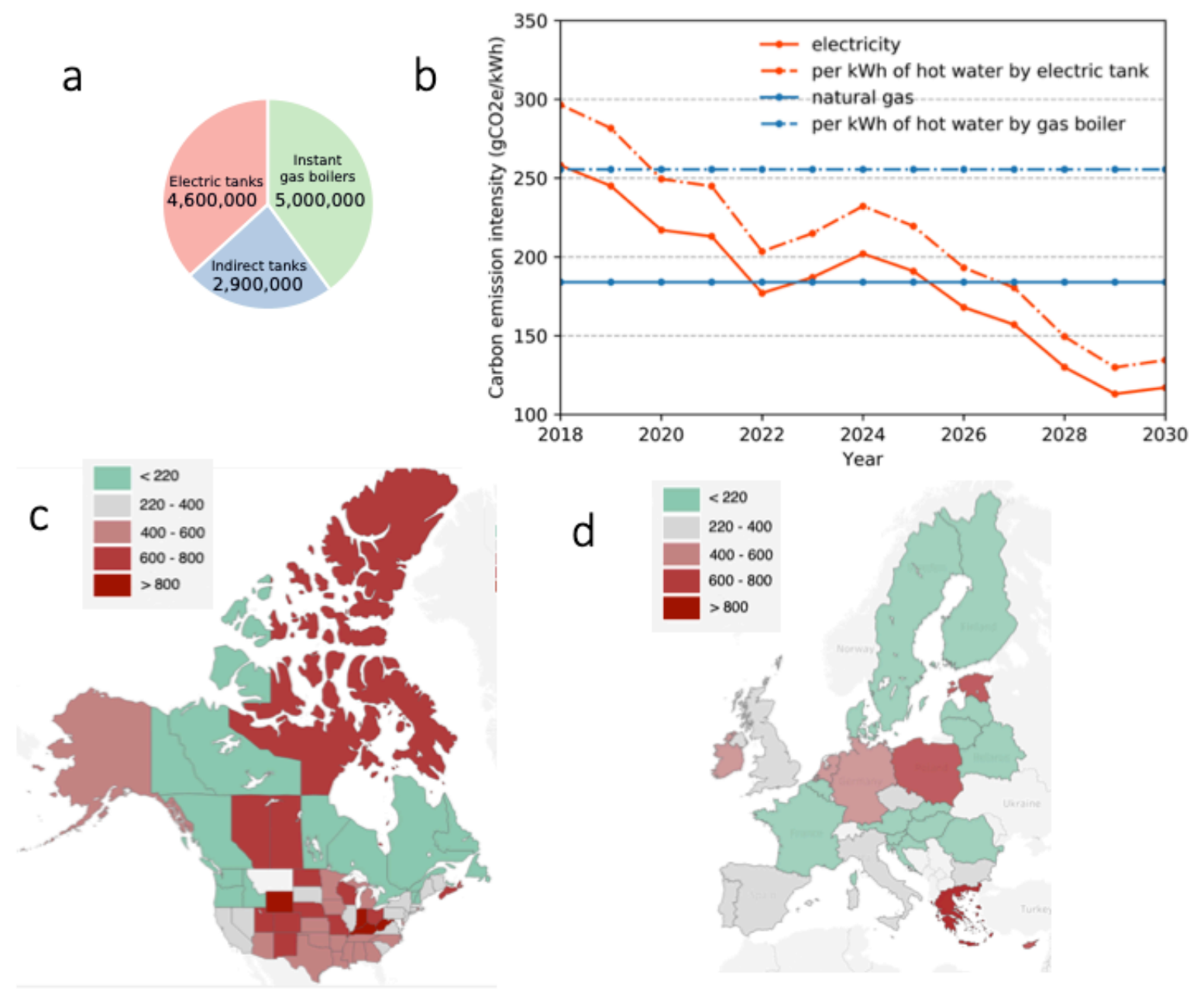

Figure 5 a: Projected distribution of sales of hot water systems in 2020 by European council prior to implementation of energy labelling scheme. $\mathbf{b}$ : Projected carbon intensity of UK electricity against natural gas including $\mathrm{gCO}_{2}$ per $\mathrm{kWh}$ of hot water from an electric hot water tank compared with an instant gas boiler based on efficiencies measured in this paper for a medium draw profile. c: Carbon intensity of electricity generation across US and Canada. d: Carbon intensity across European member state. 


\section{ii. Why is there no conversion coefficient applied to gas-fuelled hot water systems?}

The standard assumes an efficiency penalty for electrically heated tanks without considering losses associated with gas production and distribution. This is in spite of the fact that the

Table 4: Carbon intensity of grid electricity associated with Northern American and European territories

\begin{tabular}{|c|c|c|c|c|c|c|c|}
\hline \multicolumn{4}{|c|}{ United States } & \multicolumn{2}{|c|}{ Canada } & \multicolumn{2}{|c|}{ Europe } \\
\hline State & $\mathrm{gCO}_{2} / \mathrm{kWh}$ & State & $g \mathrm{CO}_{2} / \mathrm{kWh}$ & State & $\mathrm{gCO}_{2} / \mathrm{kWh}$ & Country & $\mathrm{gCO}_{2} / \mathrm{kWh}$ \\
\hline Vermont & 6 & Tennessee & 502 & Quebec & 1.3 & Sweden & 11 \\
\hline Washington & 89 & Texas & 520 & Manitoba & 1.9 & France & 35 \\
\hline $\begin{array}{l}\text { Idaho } \\
\text { New }\end{array}$ & 117 & Michigan & 522 & $\begin{array}{l}\text { British Columbia } \\
\text { Prince Edward }\end{array}$ & 11.1 & Austria & 60 \\
\hline Hampshire & 131 & Arkansas & 524 & Island & 25 & Slovakia & 89 \\
\hline Oregon & 136 & Kansas & 540 & $\begin{array}{l}\text { Ontario } \\
\text { Newfoundland }\end{array}$ & 36 & Latvia & 95 \\
\hline Maine & 222 & Alaska & 546 & and Lab & 37 & Lithuania & 103 \\
\hline South Dakota & 232 & lowa & 554 & $\begin{array}{l}\text { Yukon } \\
\text { Northwest }\end{array}$ & 45 & Finland & 106 \\
\hline New York & 232 & $\begin{array}{l}\text { Montana } \\
\text { District of }\end{array}$ & 591 & Territories & 200 & Croatia & 137 \\
\hline Connecticut & 235 & Columbia & 621 & New Brunswick & 340 & Denmark & 167 \\
\hline California & 238 & Wisconsin & 628 & Saskatchewan & 660 & Slovenia & 178 \\
\hline $\begin{array}{l}\text { New Jersey } \\
\text { South }\end{array}$ & 271 & Nebraska & 629 & Nova Scotia & 680 & Hungary & 207 \\
\hline Carolina & 288 & Colorado & 661 & Nunavut & 750 & Romania & 209 \\
\hline Nevada & 365 & Ohio & 685 & Alberta & 760 & Belgium & 212 \\
\hline Illinois & 385 & New Mexico & 703 & & & Belarus & 212 \\
\hline Virginia & 394 & Hawaii & 728 & & & Italy & 229 \\
\hline $\begin{array}{l}\text { Pennsylvania } \\
\text { Massachusett }\end{array}$ & 395 & Utah & 739 & & & Luxembourg & 268 \\
\hline $\begin{array}{l}\text { S } \\
\text { North }\end{array}$ & 397 & North Dakota & 788 & & & Spain & 304 \\
\hline Carolina & 401 & Missouri & 797 & & & Portugal & 360 \\
\hline Alabama & 405 & Indiana & 837 & & & Bulgaria & 370 \\
\hline Rhode Island & 406 & West Virginia & 900 & & & $\begin{array}{l}\text { United } \\
\text { Kingdom }\end{array}$ & 389 \\
\hline Arizona & 409 & Kentucky & 900 & & & $\begin{array}{l}\text { Czech } \\
\text { Republic }\end{array}$ & 389 \\
\hline Mississippi & 417 & Wyoming & 945 & & & Germany & 425 \\
\hline Georgia & 450 & & & & & Netherlands & 451 \\
\hline Florida & 462 & & & & & Ireland & 456 \\
\hline Oklahoma & 471 & & & & & Poland & 671 \\
\hline Louisiana & 494 & & & & & Cyprus & 684 \\
\hline Minnesota & 497 & & & & & Malta & 715 \\
\hline Delaware & 498 & & & & & Estonia & 762 \\
\hline Maryland & 499 & & & & & Greece & 830 \\
\hline
\end{tabular}


energy return on energy invested (EROEI) into oil and gas extraction has declined by nearly $50 \%$ over the past two decades ${ }^{26}$. Comprehensive data on EROEl figures for natural gas are hard to obtain but vary from anywhere between $100: 1$ and $25: 1^{27}$. Furthermore, additional externalities are not considered such as the fugitive emissions of methane which has a global warming potential ranging anywhere between 28 to 36 times that of $\mathrm{CO}_{2}$ over a 100year time horizon ${ }^{28}$. It is therefore arguable that a CC factor should also be applied to the fuel source in Equation 1 to account for these externalities, however, this would be problematic due to the complexities around comparing different sources of gas with different distribution methods and so is not advanced as a solution in this paper.

iii. Why is the notion of a power source conversion coefficient not applied to other appliances?

The idea of using a conversion coefficient for electric hot water tanks is at odds with the approach taken with other product types. For instance, many domestic ovens are heated by a combination of gas, electricity or a mixture of the two sources, however, there is no conversion coefficient associated with electricity for these products ${ }^{29}$. On the other hand, the EU2015/1188 directive governing local space heaters does apply a CC value of 2.5 to electricity usage ${ }^{30}$. The application of the $\mathrm{CC}$ parameter is therefore not consistent across the board for domestic appliances. Given the potential benefits associated with demand response within electric hot water tanks, discussed in Section 1, it is anomalous that they should be uniquely penalised.

iv. Is it right for a product standard to determine energy policy across the whole of the European Union?

There is a broader policy question around whether individual product standards are the right forum to influence energy consumption policy across the whole of the European Union. Individual member states may take a different view of their own energy policy 
depending upon the natural resources available to them. For instance, it may make more sense to use heat-pumps and solar collectors to heat water in Spain, where higher solar irradiation and ambient temperatures will lead to greater collector yields and coefficients of performance, on the other hand, Norway may prefer to heat tanks electrically via their incumbent hydro capacity where lower levels of sunlight and lower ambient temperatures prevail.

v. Is a policy that mitigates against electric hot water storage sensible from the perspective of an energy system encountering a higher share of renewables

The European Commission has a stated goal to ensure that $27 \%$ of the continent's energy consumption is delivered from renewable energy sources by $2030^{30}$. However, constraints are already being encountered within Europe's power infrastructure, particularly as surplus renewable generation from within Germany is overloading power lines in neighbouring countries $^{31}$. Encouraging more intelligent timing of local energy consumption through demand-side response will help alleviate network constraints which in turn facilitates more renewable production ${ }^{32}$. However, the current energy labelling scheme discriminates against the installation of electric hot water tanks which are ideal devices for facilitating domestic level demand side response due to their considerable thermal inertia.

\section{Conclusions and policy implications}

There is a disconnect between the ambitions that governments profess with respect to climate policy and the standards which determine white goods and building specifications. This paper has demonstrated that a market leading electric hot water tank outperforms an A rated instantaneous gas boiler in terms of energy efficiency by $14 \%$ over a standardised draw cycle. In spite of this, the European energy labelling directive awards a $\mathrm{C}$ rating to the 
electric hot water tank by imposing a conversion coefficient to account for an assumed $40 \%$ generation and distribution efficiency associated with electricity. This is in spite of the fact that in nine European states the carbon intensity of electricity is now lower than gas; a number projected to increase as Europe moves towards its goal of delivering $27 \%$ of its energy requirements from renewables by 2030 .

By encouraging householders to purchase instantaneous gas boilers over electric hot water tanks, Europe is locking its citizens into a future of higher carbon emissions. We argue for the removal of the conversion coefficient from standard EU 812/2013. This would level the playing field between electric hot water tanks and instantaneous gas boilers. As it stands, the energy labelling directive is undermining an opportunity to facilitate more renewable integration through the use of electric hot water tanks which are uniquely suited to absorbing surplus renewable power. Standard bodies need to become more proactive in recognising the developments in our energy system and how this will influence the emissions associated with dwellings and their heating systems.

\section{References}

1 Intergovernmental Panel on Climate Change, Global Warming of $1.5^{\circ} \mathrm{C}$ : Summary for Policymakers. 2018: Incheon, Republic of Korea.

2 Verbeke, S. and A. Audenaert, Thermal inertia in buildings: A review of impacts across climate and building use. Renewable and Sustainable Energy Reviews, 2018. 82: p. 23002318.

3 Armstrong, P. \& McCulloch, M. in IEEE PES Innovative Smart Grid Technologies Europe (ISGT) (Istanbul, 2014).

4 Söder, L., et al., A review of demand side flexibility potential in Northern Europe. Renewable and Sustainable Energy Reviews, 2018. 91: p. 654-664.

5 Spence, A., Demski, C., Butler, C., Parkhill, K. \& Pidgeon, N. Public perceptions of demandside management and a smarter energy future. Nature Climate Change 5, 550-554, doi:10.1038/nclimate2610 (2015).

6 Fu, C., et al., Thermal efficiency of coal-fired power plants: From theoretical to practical assessments. Energy Conversion and Management, 2015. 105: p. 530-544.

7 Schonek, J. How big are Power line losses? 2013 [cited 201826 Oct]; Available from: https://blog.schneider-electric.com/energy-management-energyefficiency/2013/03/25/how-big-are-power-line-losses/. 
ENERGY STAR ${ }^{\circledR}$ Residential Water Heaters: Final Criteria Analysis. 2008, Energy Star. p. 11. Assessment Procedure for Energy Rating of Dwellings. 2012, Building Research Establishment: Watford, United Kingdom. p. 234.

The European Commission. Commission delegated regulation (EU) No. 812/2013 supplementing directive 2010/30/EU of the European Parliament and of the Council with regard to the energy labelling of water heaters, hot water storage tanks and packages of water heater and solar device (Brussels, 2013).

Keston Boilers. Keston C36 Combi modulating condensing combination gas fired boiler: User, Installation and Servicing instructions (Kent, UK, 2010).

British Standards Institute. BS EN 50440:2015: Efficiency of domestic electrical storage water heaters and testing methods (London, UK, 2015).

Taylor, J. R.Ch. Independent versus dependent measurements in An Introduction to Error Analysis, Second Ed. (University Science Books, 1977), pp. 45-79.

Monthly average daily temperatures in the United Kingdom (UK) from 2013 to 2018 (in degrees Celsius). 2018 [cited 201820 Sep]; Available from:

https://www.statista.com/statistics/322658/monthly-average-daily-temperatures-in-theunited-kingdom-uk/. (2018).

Domestic building services compliance guide. 2013, HM Government, (London, UK, 2013). Study on the impact of the energy label - and potential changes to it - on consumer understanding and on purchase decisions. (London Economics, London, UK, 2014). van Blommestein, K.C. and T.U. Daim, Residential energy efficient device adoption in South Africa. Sustainable Energy Technologies and Assessments, 2013. 1: p. 13-27.

Government GHG conversion factors for company reporting, Department for Business, Energy \& Industrial Strategy (London, UK, 2018).

European Environment Agency. Overview of electricity production and use in Europe. 27 (Copenhagen, Denmark, 2018).

Kaldellis, J. K., Zafirakis, D. \& Kondili, E. Contribution of lignite in the Greek electricity generation: Review and future prospects. Fuel 88, 475-489, doi:10.1016/j.fuel.2008.09.021 (2009).

1 European Environment Agency. Electricity generation CO2 emission intensity. [cited 201820 Sep]; Available from: https://www.eea.europa.eu/data-and-maps/daviz/co2-emissionintensity-3\#tab-chart_2 (2016).

2 Moro, A. \& Lonza, L. Electricity carbon intensity in European Member States: Impacts on GHG emissions of electric vehicles. Transportation Research Part D: Transport and Environment, doi:10.1016/j.trd.2017.07.012 (2017). U. S. Energy Information Administration. State Electricity Profiles. 2018 [cited 20181 Nov]; Available from: https://www.eia.gov/electricity/state/arkansas/index.php.

National Grid. Carbon Intensity API, <http://carbonintensity.org.uk/> (2018). Element Energy Limited. Hybrid heat pumps: Final report for Department for Business, Energy \& Industrial Strategy. (Cambridge, UK, 2017).

Gagnon, N., Hall, C. \& Brinker, L. A Preliminary Investigation of Energy Return on Energy Investment for Global Oil and Gas Production. Energies 2, 490-503, doi:10.3390/en20300490 (2009).

Hall, C. A. S., Lambert, J. G. \& Balogh, S. B. EROl of different fuels and the im
society. Energy Policy 64, 141-152, doi:10.1016/j.enpol.2013.05.049 (2014). United States Environmental Protection Agency. Understanding Global Warming Potentials. (2018).

The European Commission. Commission delegated regulation (EU) No. 66/2014 implementing Directive 2009/125/EC of the European Parliament and of the Council with regard to ecodesign requirements for domestic ovens, hobs and range hoods (Brussels, 2014). 
30 30. The European Commission. Commission delegated regulation (EU) No. 2015/1188 implementing Directive 2009/125/EC of the European Parliament and of the Council with regard to ecodesign requirements for local space heaters (Brussels, 2015).

31 Janda, K., Málek, J. \& Rečka, L. Influence of renewable energy sources on transmission networks in Central Europe. Energy Policy 108, 524-537, doi:10.1016/j.enpol.2017.06.021 (2017).

32 International Energy Agency (2011). Technology Roadmap Energy-efficiency Buildings: Heating and Cooling Equipment. Paris, France.

\section{Acknowledgements}

This research was funded by the 'Domestic Energy Storage Integrating Renewable Energy' project, awarded to the University of Oxford by the Innovate UK, under project reference: 103307. The authors thank Peter Dobson for useful comments on the manuscript.

\section{Author contributions}

P. M. A. and S.M.B. jointly designed the study and wrote the paper with iterative feedback from M.M.; P.M.A. and R.K. performed the experiments and calculations.

\section{Competing interests}

The authors declare no competing interests. 